\title{
An Investigation of the Influences of the Voltage Sag on the Doubly Fed Induction Generator using Tuned PI Controllers
}

\author{
Zahra RAFIEE, Mansour RAFIEE, Mohammadreza AGHAMOHAMMADI
}

\begin{abstract}
The paper presents dynamic and transient behavior of the doubly fed induction generator (DFIG) in the wind farms in the normal and faulted grid respectively. When Voltage sag or any fault occurs in the network, the variables in the Doubly Fed Induction Generators are varying severely. If a voltage sag occurs, active and reactive power generated by the DFIG start to oscillate. The DC-link voltage will be bigger and will have fluctuation, and the rotor current will increase. In this paper, proportional integral (PI) controllers are used to control the DFIG in the wind farms for driving of the electronic devices including Rotor Side Converter (RSC) and Grid Side Converter (GSC) and controlling the active and reactive power of DFIG. PI parameters are tuned by particle swarm optimization algorithm (PSO). Whereas the model of DFIGs and electronic device in the paper are nonlinear so PI controllers cannot protect and control the DFIG as well. Hence, effect of PI parameters is investigated on the DFIG with simulating in MATLAB software. Also, low voltage ride through (LVRT) feature for DFIG is explored in presence of PI controllers. The results of the simulation present DClink over voltage and rotor and stator over current in the DFIG. In addition, it will explore the effect of proportional integral controllers when three-phase short circuit fault occurs.
\end{abstract}

Keywords: doubly fed induction generator; fault ride through; low voltage ride through; voltage sags

\section{INTRODUCTION}

In recent years, using wind energy for generating electricity is growing fast because it is an important source of renewable energy [1]. With increasing penetration level of wind energy into the network, wind turbine should remain connected to the grid to maintain the reliability during various grid fault scenarios based on grid codes' requirement [2]. DFIG is predominantly used nowadays in the wind turbines. Important issues when the DFIG-based wind turbine (WT) connected to the network is the transient behavior in a faulted grid. The DFIG-based WT is very sensitive to the grid disturbances[3]. Based on the grid codes' requirement, the DFIG-based WT must stay connected to the network and actively support the voltage stability in faulty grid [4]. The ability of the wind turbines to remain connected to the network during the voltage dips is called the low voltage ride through (LVRT) capability and fault ride through (FRT) capability respectively $[5,6]$.

When a voltage sag occurs in the DFIG-based WT, two major issues are generated in the DFIG-based WT. The first one is rotor and stator over-current, and the second one is DC-link over-voltage. Because the converters in the DFIG-based WT have a relatively low power rating, they cannot undergo over-currents and over-voltages. Also, the DC-Link capacitor is damaged when the over-voltage occurs. Hence, studying the LVRT capability of the DFIGbased wind farms is the special interest with respect to the stability issue of such system [7]. In addition, the passive LVRT capability method, as well as the active LVRT capability strategy have been developed for the subject of transient analysis of the DFIG [8]. Therefore, dynamic modelling has been developed for the LVRT capability using demagnetization current controller [9].

Many of research activities over the world focus on the impact of the system disturbances on the DFIG-based wind farms in the fault conditions [10]. So, they have proposed using a crowbar resistor to suppress rotor over-current and a DC chopper to smooth DC-link over-voltage as the first solution in the fault conditions [11]. The conventional crowbar circuit installed across the rotor terminals causes the rotor of the DFIG to become short circuit when a fault occurs. Consequently, the rotor is blocked and the DFIG starts absorbing reactive power from the faulted grid. But the new model of the crowbar resistance only limits the current during the fault so based on the conventional crowbar protection, many of researchers have improved the crowbar circuit. They control the crowbar circuit with the power electronic devices and new methods of control [12]. Some of the researchers improve the structure of DC chopper for reducing the DC-link over-voltage [13] or some papers present devices which absorb DC-link overvoltage [14].

Dynamic control of DFIG enhances wind farm penetration into the network. Hence, Flywheel control using Flux magnitude and angle control for power and voltage stabilization has been used [15] and for wind power smoothing such as the effects of wind fluctuations on system voltage and frequency, a hybrid energy storage system including a super capacitor and a flow battery is presented in a DFIG-based WT [16]. In addition, ESS and DC chopper circuit regulate generator output power in the grid-side converter and DC-link for improving FRT capability [17].

Moreover, the usage of the fault current limiters and the energy storage system actually install extra hardware in the DFIG and can increase the costs and decrease the system reliability but the crowbar resistance and DC chopper are necessary for the protection systems [6]. Some researchers also have proposed other hardware for enhancing the LVRT capability. These strategies reduce the rotor over-current and the DC-link over-voltage in faulted grids. Also, they designed more advanced control strategies for the RSC and the GSC [18]. However, some of these algorithms are too complicated and control parameters must be chosen properly and precisely. For example, the robust nonlinear controller using the Hamiltonian controller in the presence of disturbances for the DFIG is proposed in [19]. In [20] has been proposed a control strategy to maximize the wind energy captured in a DFIG, at low to medium wind speeds. To avoid dealing with the zero dynamic limitation brought by the bidirectional power flow through the RSC and the GSC in a DFIG, a new energy-based modeling and control scheme for the GSC is proposed in [21]. The other auxiliary hardware applications try to remain the wind farms 
connected to the grid during fault conditions such as a stator dynamic composite fault current limiter (SDCFCL) in the stator [22], using simultaneously a DC-Chopper and a Series Dynamic Resistors (SDR) [13], a super capacitor energy storage system connected to the point of common coupling (PCC) [23], a STATCOM connected to PCC [24], a bridge type fault current limiter connected to the PCC [25], a dynamic voltage restorer [26], DC-link switchable resistive-type fault current limiter (SRFCL) [27], an active crowbar protection (ACB P) in the rotor [28], a new statordamping resistor unit (SDRU) and rotor current control (RCC) [29], and etc. Moreover, using hardware strategies actually installs extra hardware in the DFIG and can increase the costs and may reduce the reliability of the system. So, in $[30,31]$ a novel LVRT capability strategy is enhanced using sliding mode in DFIG-based wind farm without installing extra hardware.

This paper presents effects of a voltage sag event on the rotor and stator of the DFIG. Then, using PI controllers control the RSC, GSC, DC-link and pitch control for reducing over-current and over-voltage in a faulted grid. Also, the effect of PI controllers' parameters on DC-link over-voltage and rotor over-current are presented. In addition, this paper uses particle swarm optimization algorithm for tuning PI parameters and then the new PI parameters are validated by varying the reference of active and reactive power. This paper is organized as follows: in section 2, the modelling of the DFIG-based WT is introduced. In section 3, based on PI controllers of DFIG, the principle of the proposed method is described. Then, in section 4, the simulation results by MATLAB/ SIMULINK $^{@}$ are shown to validate the proposed method.

\section{DFIG-BASED WIND FARM MODEL}

It is necessary to examine the exchange of the active and reactive power between a DFIG-based wind farm and an electrical network using a precise model. The schematic diagram of a DFIG-based wind farm system connected to the grid is shown in Fig. 1. The DFIG-based WT, including the doubly fed induction generator, three-bladed wind turbine, the back-to-back converters (GSC and RSC), the drive train, and the control systems, are connected to the network through a three-phase transformer. The control system consists of three control parts: the DFIG control, the WT control, and the WF control. The reference value of the rotor speed of the DFIG based on the measured wind speed and the reference value for active power is tuned by the WT controls which adjust mechanical power of the wind turbine through the pitch angle [32]. The DFIG control part, including the RSC and GSC controllers, and the voltage regulator for the DC-link control the active and reactive power of the DFIG using the PI controllers.

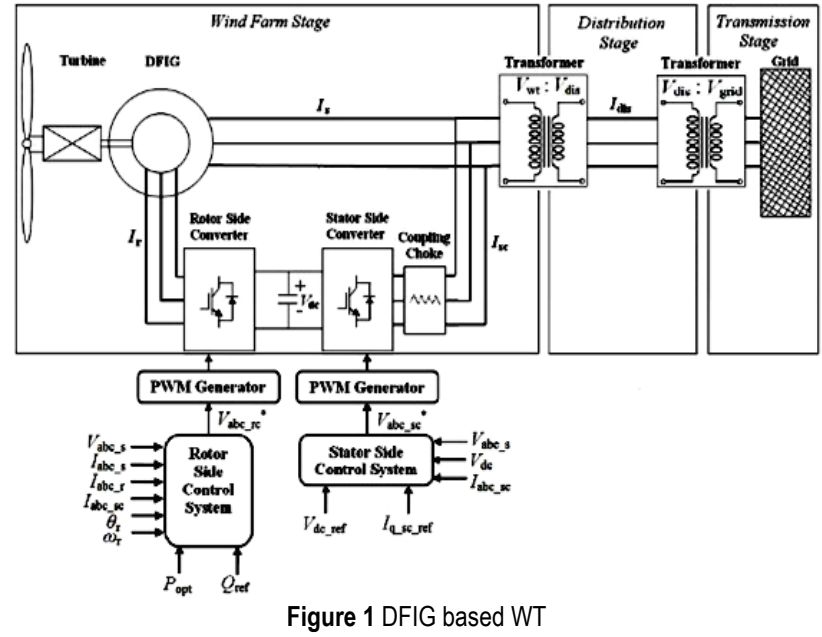

\subsection{DFIG Dynamic Model}

The voltage equations specified in a DFIG in the synchronous reference frame are presented as

$\left\{\begin{array}{l}u_{s}=R_{s} i_{s}+\frac{\mathrm{d} \lambda_{s}}{\mathrm{~d} t}+j \omega_{e} \lambda_{s} \\ u_{r}=R_{r} i_{r}+\frac{\mathrm{d} \lambda_{r}}{\mathrm{~d} t}+j\left(\omega_{e}-\omega_{r}\right) \lambda_{r}\end{array}\right.$

By simplifying the voltage equations described above, the flux equations can be shown as

$$
\left\{\begin{array}{l}
\frac{\mathrm{d} \lambda_{s}}{\mathrm{~d} t}=u_{s}-R_{s} i_{s}-j \omega_{e} \lambda_{s} \\
\frac{\mathrm{d} \lambda_{r}}{\mathrm{~d} t}=u_{r}-R_{r} i_{r}-j\left(\omega_{e}-\omega_{r}\right) \lambda_{r}
\end{array}\right.
$$

In order to investigate the behaviour of the DFIG the flux and current equations of the stator and the rotor must be used. Therefore, the transient flux relations are extracted and expressed in terms of current as:

$$
\begin{aligned}
& i_{s}=\frac{L_{r}}{\left(L_{l s} \cdot L_{l r}+L_{l s} \cdot L_{m}+L_{l r} \cdot L_{m}\right)} \times \lambda_{s}-\frac{L_{m}}{\left(L_{l s} \cdot L_{l r}+L_{l s} \cdot L_{m}+L_{l r} \cdot L_{m}\right)} \times \lambda_{r} \\
& i_{r}=\frac{-L_{m}}{\left(L_{l s} \cdot L_{l r}+L_{l s} \cdot L_{m}+L_{l r} \cdot L_{m}\right)} \times \lambda_{s}+\frac{L_{s}}{\left(L_{l s} \cdot L_{l r}+L_{l s} \cdot L_{m}+L_{l r} \cdot L_{m}\right)} \times \lambda_{r}
\end{aligned}
$$

Space state equations of the DFIG can be used to check the behaviour of DFIG-based wind farm in the event of various faults in the network:

$$
\left\{\begin{array}{l}
\frac{\mathrm{d} \lambda_{s}}{\mathrm{~d} t}=u_{s}-R_{s}\left(\frac{L_{r}}{\left(L_{l s} \cdot L_{l r}+L_{l s} \cdot L_{m}+L_{l r} \cdot L_{m}\right)} \times \lambda_{s}\right)+R_{s}\left(\frac{L_{m}}{\left(L_{l s} \cdot L_{l r}+L_{l s} \cdot L_{m}+L_{l r} \cdot L_{m}\right)} \times \lambda_{r}\right)-j \omega_{e} \lambda_{s} \\
\frac{\mathrm{d} \lambda_{r}}{\mathrm{~d} t}=u_{r}-R_{r}\left(\frac{-L_{m}}{\left(L_{l s} \cdot L_{l r}+L_{l s} \cdot L_{m}+L_{l r} \cdot L_{m}\right)} \times \lambda_{s}\right)-R_{r}\left(\frac{L_{s}}{\left(L_{l s} \cdot L_{l r}+L_{l s} \cdot L_{m}+L_{l r} \cdot L_{m}\right)} \times \lambda_{r}\right)-j\left(\omega_{e}-\omega_{r}\right) \lambda_{r}
\end{array}\right.
$$


Finally, the space state equations of the DFIG in the synchronous reference can be expressed as:

$$
\left\{\begin{array}{l}
\frac{\mathrm{d} \lambda_{s d}}{d t}=u_{s d}-R_{s}\left(\frac{L_{r}}{\left(L_{l s} \cdot L_{l r}+L_{l s} \cdot L_{m}+L_{l r} \cdot L_{m}\right)} \times \lambda_{s d}-\frac{L_{m}}{\left(L_{l s} \cdot L_{l r}+L_{l s} \cdot L_{m}+L_{l r} \cdot L_{m}\right)} \times \lambda_{r d}\right)+j \omega_{e} \lambda_{s q} \\
\frac{\mathrm{d} \lambda_{s q}}{d t}=u_{s q}-R_{s}\left(\frac{L_{r}}{\left(L_{l s} \cdot L_{l r}+L_{l s} \cdot L_{m}+L_{l r} \cdot L_{m}\right)} \times \lambda_{s q}-\frac{L_{m}}{\left(L_{l s} \cdot L_{l r}+L_{l s} \cdot L_{m}+L_{l r} \cdot L_{m}\right)} \times \lambda_{r q}\right)-j \omega_{e} \lambda_{s d} \\
\frac{\mathrm{d} \lambda_{r d}}{\mathrm{~d} t}=u_{r d}-R_{r}\left(\frac{L_{m}}{\left(L_{l s} \cdot L_{l r}+L_{l s} \cdot L_{m}+L_{l r} \cdot L_{m}\right)} \times \lambda_{s d}+\frac{L_{s}}{\left(L_{l s} \cdot L_{l r}+L_{l s} \cdot L_{m}+L_{l r} \cdot L_{m}\right)} \times \lambda_{r d}\right)+j\left(\omega_{e}-\omega_{r}\right) \lambda_{r q} \\
\frac{\mathrm{d} \lambda_{r q}}{\mathrm{~d} t}=u_{r q}-R_{r}\left(\frac{L_{s}}{\left(L_{l s} \cdot L_{l r}+L_{l s} \cdot L_{m}+L_{l r} \cdot L_{m}\right)} \times \lambda_{s q}+\frac{L_{l s}}{\left(L_{l s} \cdot L_{l r}+L_{l s} \cdot L_{m}+L_{l r} \cdot L_{m}\right)} \times \lambda_{r q}\right)-j\left(\omega_{e}-\omega_{r}\right) \lambda_{r d}
\end{array}\right.
$$

\subsection{Symmetrical Voltage Dip}

When the voltage of the PCC drops due to a voltage sag in a faulted network, the induced motive force in the rotor frame is derived by the following equation

$E M F_{r}^{r}=\frac{L_{m}}{L_{s}}\left[s V_{s}(1-g) \mathrm{e}^{j\left(\omega_{e}-\omega_{r}\right) t}-\frac{V_{s} g}{j \omega_{s}}\left(\frac{1}{\tau_{s}}-j \omega_{r}\right) \mathrm{e}^{-j \omega_{r} t} \mathrm{e}^{\frac{-t}{\tau_{s}}}\right]$

Regardless of $1 / \tau_{s},(7)$ can be presented as

$$
E M F_{r}^{r}=\frac{L_{m}}{L_{s}}\left[s V_{s}(1-g) \mathrm{e}^{j\left(\omega_{e}-\omega_{r}\right) t}-V_{s} g(1-s) \mathrm{e}^{-j \omega_{r} t} \mathrm{e}^{\frac{-t}{\tau_{s}}}\right]
$$

From (8), it can be seen that the induction EMF amplitude is relatively large in the initial moment of the fault due to the DC offset in the flux. For example, if $s=$ -0.2 and $g=1$, the amplitude of the EMF is $1.2 V_{s} L_{m} / L_{s}$ in the initial moments, which is 6 times the normal value. Fig. 2 shows the induced EMF variation in the rotor due to changes in the stator flux.

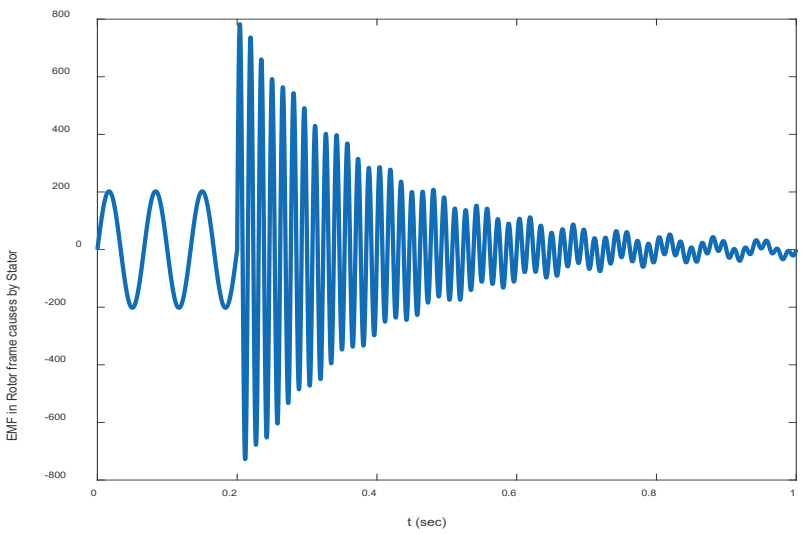

Figure 2 The inducted EMF fluctuations in the rotor due to fluctuations in the stator flux

The purpose of the RSC controller is to control the DFIG active and reactive power for tracking their reference values, and to preserve the terminal voltage. The active and reactive power are controlled independently by $u_{d r}$ and $u_{q r}$, respectively. So, the control equations are given as:

$$
\begin{aligned}
& \left\{\begin{array}{l}
\Delta P=P_{\mathrm{ref}}-P_{s} \\
\Delta Q=Q_{\mathrm{ref}}-Q_{s}
\end{array}\right. \\
& u_{d r}=K_{p 1} \Delta P+\frac{K_{i 1} \Delta P}{s} \\
& u_{q r}=K_{p 2} \Delta Q+\frac{K_{i 2} \Delta Q}{s}
\end{aligned}
$$

where $K_{p 1}$ and $K_{i 1}$ are the proportional and integrating gains of active power regulator; $K_{p 2}$ and $K_{i 2}$ are the proportional and integrating gains of reactive power regulator; $P_{\text {ref }}$ and $Q_{\text {ref }}$ are active and reactive power references, respectively; $P_{s}$ and $Q_{s}$ are stator active and reactive power, respectively.

The aim of the GSC controller is to maintain the DClink voltage and control the reactive power of the DFIG. The DC-link voltage and reactive power are controlled by $u_{d g}$ and $u_{q g}$, respectively. So, the control equations of the GSC are given as:

$$
\begin{aligned}
& \Delta V_{\mathrm{DC}}=V_{\mathrm{DC}_{-} \text {ref }}-V_{\mathrm{DC}} \\
& u_{d g}=\left(K_{p 4}+\frac{K_{i 4}}{s}\right)\left(K_{p 3} \Delta V_{\mathrm{DC}}+\frac{K_{i 3} \Delta V_{\mathrm{DC}}}{s}\right) \\
& u_{q g}=\left(K_{p 5}+\frac{K_{i 5}}{s}\right)\left(i_{q r_{-} \text {ref }}-i_{q r}\right)
\end{aligned}
$$

where $K_{p 4}, K_{p 3}$ and $K_{i 4}, K_{i 3}$ are the proportional and integrating gains of DC-link voltage regulator; $K_{p 5}$ and $K_{i 5}$ are the proportional and integrating gains of reactive power regulator; $i_{q r}$ ref and $i_{q r}$ are d-axis rotor current reference and $\mathrm{d}$-axis rotor current in synchronous reference frame, respectively. $V_{\mathrm{DC} \text { ref }}$ is the voltage control reference of DClink and $V_{\mathrm{DC}}$ is the DC-link voltage.

\section{THE PRINCIPLE OF PI CONTROL PROPOSED METHOD 3.1 Proposed Control Method}

The DFIG has been controlled with six PI controller blocks including two blocks for RSC and three blocks for GSC as shown as Fig. 3. There are various methods for tuning the controller parameters. In this paper, genetic algorithm has been used to design PI controllers' 
parameters. Tuning and selecting the PI parameters is done in steady-state condition and transient behaviour. Then, optimal PI parameters have been set in PI controller blocks in DFIG-based wind farm. The innovation used in this paper is the use of six PI controllers without any extra hardware strategy that causes to increase cost. Also, proposed control method is very simple and decreases the calculation content.

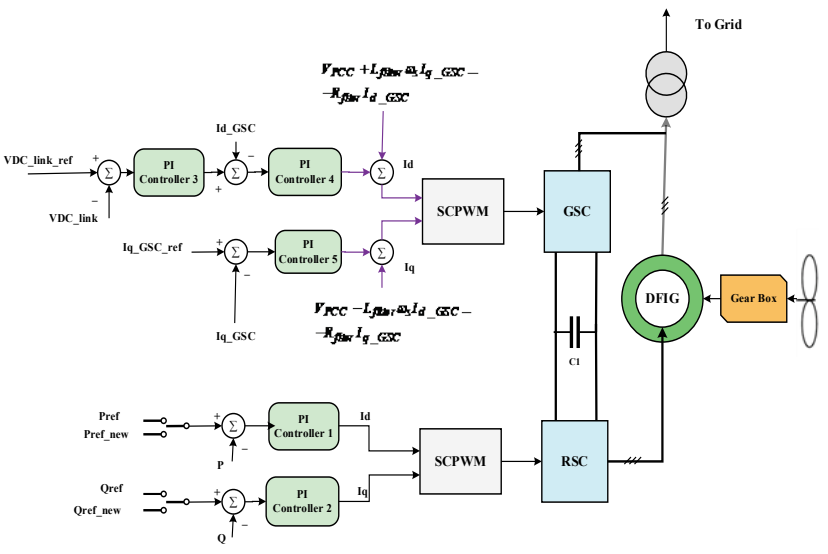

Figure 3 The proposed control method DFIG-based wind farm connected to infinite bus

\subsection{PSO Algorithm}

The PSO was first introduced by Kennedy and Eberhart (1995). It is based on the behavioural pattern of bird flocking that inspired it to look into the effect of collaboration of species, while moving as a team, a simple concept [33]. The PSO is basically developed through simulation of bird flocking. Each particle velocity is shown by $n$-dimensional vector $\boldsymbol{v}$ and each particle's position is presented by $n$-dimensional vector $\boldsymbol{s}$. The best fitness position is known as pbest and the overall best of all particles is called gbest. In each situation, each particle's modified position and velocity are calculated using each particle's position and velocity in the previous situation. The distance from the pbest to gbest is presented in Eq. (15) and (16). pbest and gbest are set on by goal function denoted in typical problem and parameters of each particle position evaluate goal function [34, 35].

The current position $\boldsymbol{s}\left(x_{1}, x_{2}, \ldots, x_{n}\right)$

The current velocities $\boldsymbol{v}\left(v_{1}, v_{2}, \ldots, v_{n}\right)$

$$
\begin{aligned}
& \boldsymbol{v}_{i}^{k+1}=\boldsymbol{v}_{i}^{k}+c_{1} \text { rand }_{1} \times\left(\text { pbest }_{i}-\boldsymbol{s}_{i}^{k}\right)+ \\
& +c_{2} \text { rand }_{2} \times\left(\text { gbest }_{i}-\boldsymbol{s}_{i}^{k}\right) \\
& \boldsymbol{s}_{i}^{k+1}=\boldsymbol{s}_{i}^{k}+\boldsymbol{v}_{i}^{k+1}
\end{aligned}
$$

where $i$ is the particle number and $k$ is the number of iteration, $n$ number of the parameters of each particle, rand random number between 0 and $1, \boldsymbol{v}_{i}^{k}$ is vector of current velocity and $\boldsymbol{s}_{i}^{k}$ is vector of current position of particle $i$ at iteration $k, \boldsymbol{g b e s t}_{i}$ is vector of gbest of all of the particles, pbest $_{i}$ is vector of pbest of particle $i, c_{i}$ is weighting factor.

\section{RESULTS AND DISCUSSIONS \\ 4.1 System under Study}

This study has used the DFIG-based wind farm connected to the infinite bus for explaining the transient behavior of the DFIG-based wind farm in a voltage sag event. The single line diagram of the test system is shown in Fig. 4. The parameters of the DFIG based WT are listed in Appendix.

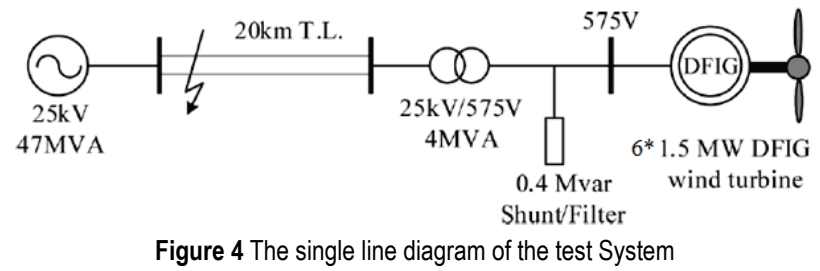

\subsection{Fault}

A three-phase fault occurs in the grid. Thus this type of fault causes a voltage dip in PCC of the DFIG. Values of voltage dip are 0.5 per unit and it takes 300 milliseconds and occurs in $t=5 \mathrm{~s}$. $700 \mathrm{~ms}$ lasts until voltage recovers to 1 per unit smoothly.

\subsection{Simulation Results}

In this section, the effect of the removal and incorrect adjustment of each proportional-integral controller - There are five PI controllers - they are explored in the DFIGbased wind farm operation and importance of each of them is determined.

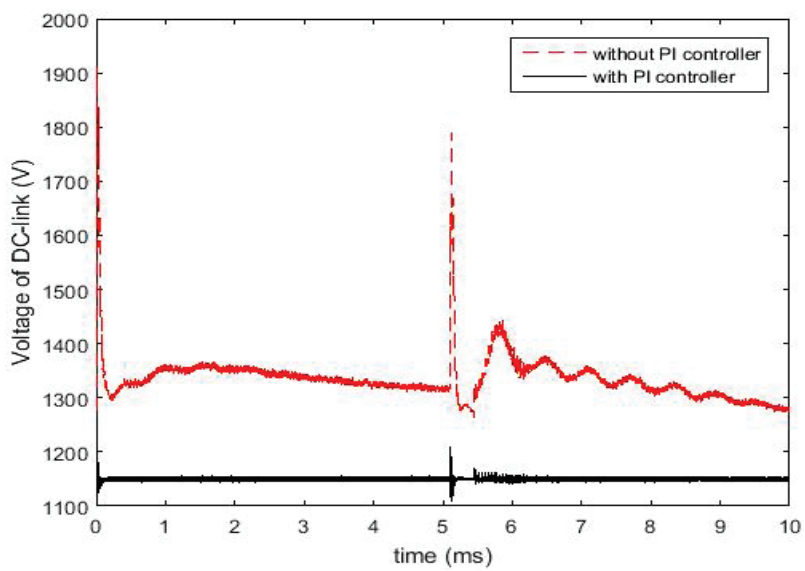

Figure 5 The DC-link voltage between the back-to-back converters with and without $\mathrm{PI}$ controllers 3 and 4

The results of the simulation have been prepared with PI controllers for driving the RSC and PI controllers to regulate the DC-link voltage and driving the GSC. In Fig. 5 , the DC-link voltage regulated by the PI controllers can be seen. As curves present, when the PI controller derives the RSC, the DC-link voltage is reduced to reference value. In this Fig, according to Fig. 3, the PI controllers 3 and 4 have not been correctly set. Fig. 6 presents the active power with and without PI controller in RSC. In this figure, the PI controllers 1 and 2 have been omitted. As it can be seen, when the PI controllers are omitted for the RSC, active power is tuned and does not change because there are PI 
controllers in the GSC and they control the active power. Fig. 7 presents the reactive power with and without the PI controllers for the RSC. In this Fig, the PI controllers 1 and 2 have been omitted. As, it can be seen in Fig 7, even though the PI controller has been eliminated, the reactive power is tuned because of the existence of PI controllers regulators for the GSC. Fig. 8 also presents the PCC voltage. For this scenario the PI controllers are considered for the RSC and the GSC.

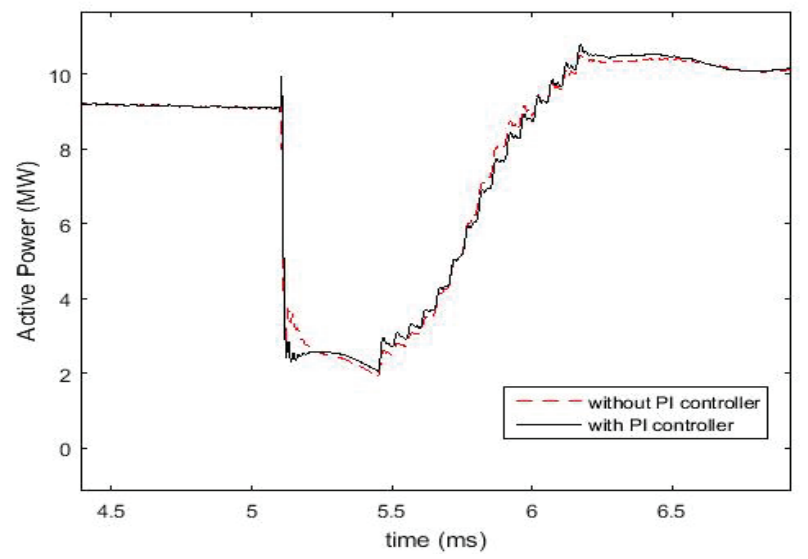

Figure 6 The active power of the DFIG-based WT with and without PI controllers 1 and 2

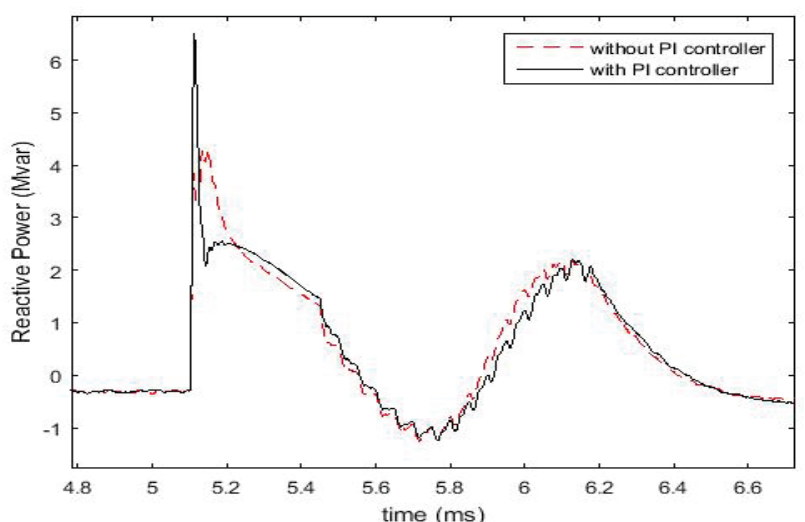

Figure 7 The reactive power that DFIG based WT generates with and without PI controllers 1 and 2

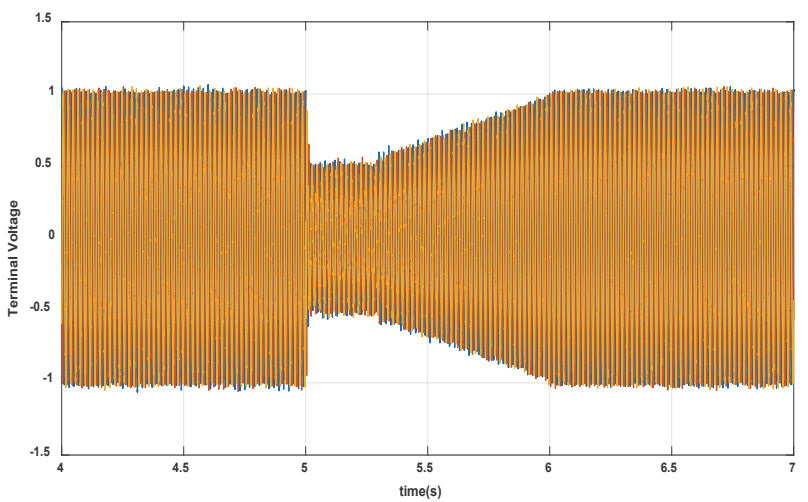

Figure 8 The voltage of the PCC in the DFIG-based wind farm

If there is no PI controller for RSC and GSC to regulate DC-link voltage, pitch angle, active power, and reactive power, DC-link voltage, active power, and reactive power would be presented in Fig. 9, Fig. 10 and Fig. 11, respectively. In these Figs, the PI controllers 1 and 5 have been omitted. It can be concluded that if PI controllers have been eliminated, the DFIG cannot work well and it cannot be used in the electrical network. In this study, the nonlinear DFIG has been modelled with some hypothesizes: (1) the omission of uncertainty in the DFIG model, (2) the consideration of the fourth order model of DFIG (3) the constant generator speed and turbine input torque. So, this study is approximate. Despite these hypotheses, in a voltage dip condition, the rotor currents increase severely as depicted in Fig. 12.

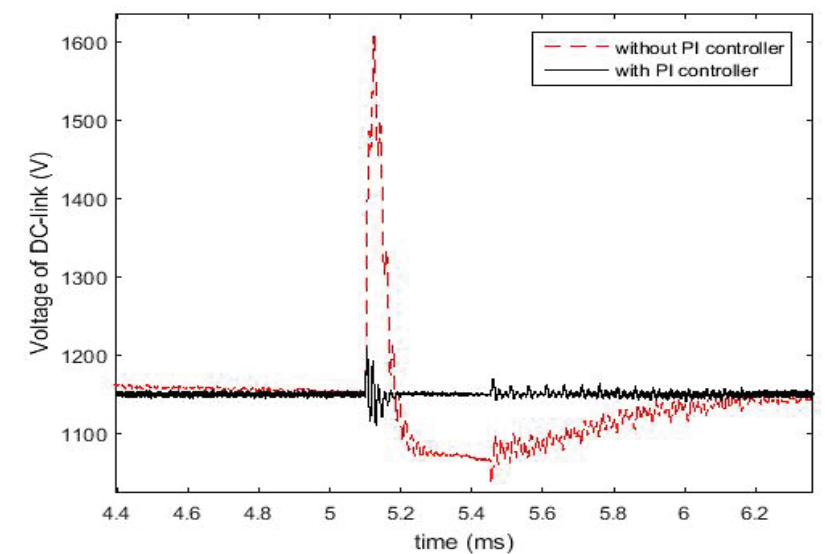

Figure 9 The voltage of the DC-link with and without the PI controllers 1 and 5 in the RSC and the GSC

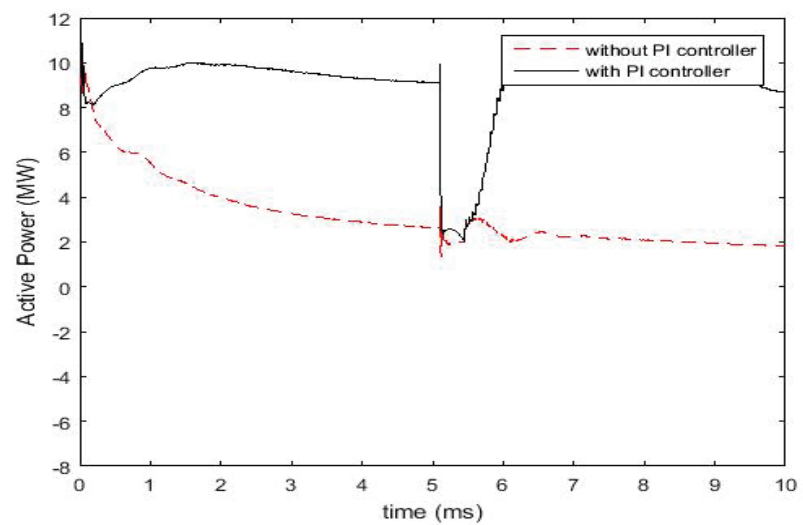

Figure 10 The active power with and without the PI controllers 1 and 5 in the $\mathrm{RSC}$ and the GSC

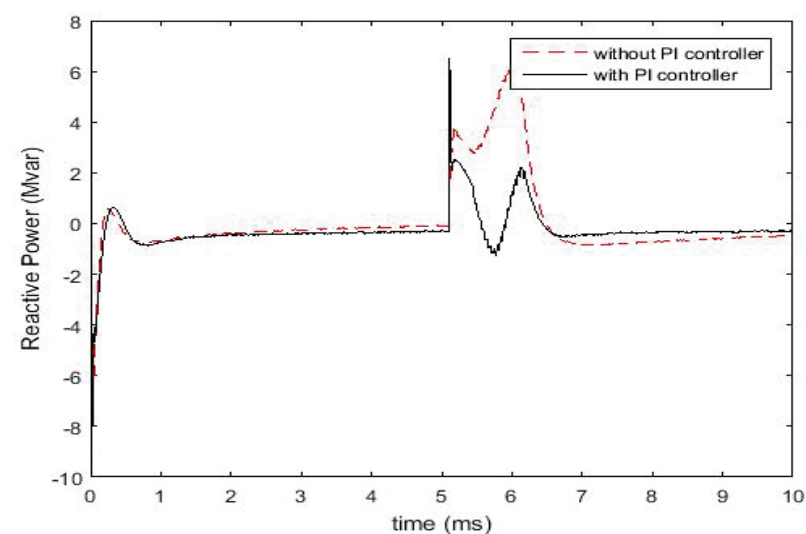

Figure 11 The reactive power with and without the PI controllers 1 and 5 in the RSC and the GSC 


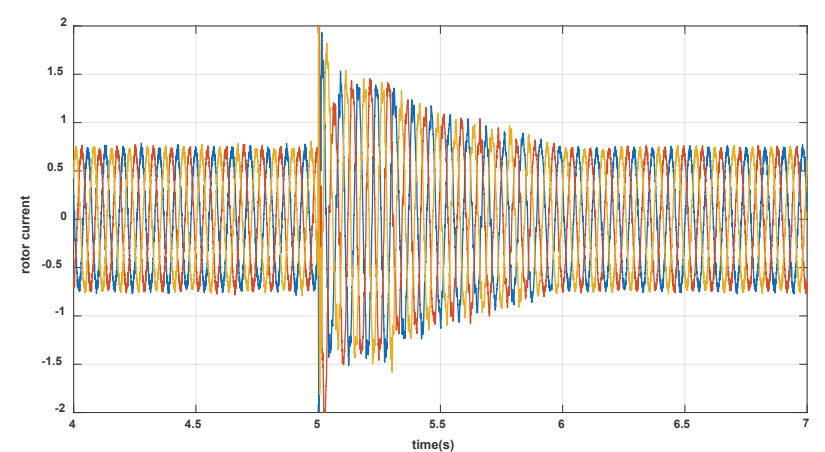

Figure 12 The rotor currents with existence of PI controllers in a fault condition.

\subsection{Result of Tuning of PI Parameters using PSO Algorithm}

In this section after tuning PI parameters in the normal condition using PSO algorithm in $t=5 \mathrm{~ms}$, a three-phase symmetric fault occurs in the network. The fault duration is 300 milliseconds and it causes a dip of $40 \%$ at the generator terminal as shown in Fig. 13. In addition to voltage dip event, in this section, the system response to a more realistic wind speed turbulences is studied [36]. In this scenario, $16.56 \%$ step change of mechanical torque causing wind speed variation changes over a certain period $4 \mathrm{~s} \leq t \leq 5.4 \mathrm{~s}$. In this case, similar to previous section, the nonlinear DFIG has been modelled with some hypotheses; (1) the omission of uncertainty in the DFIG model and added uncertainty at wind speed, (2) the consideration of fifth order model of DFIG-based wind turbine.

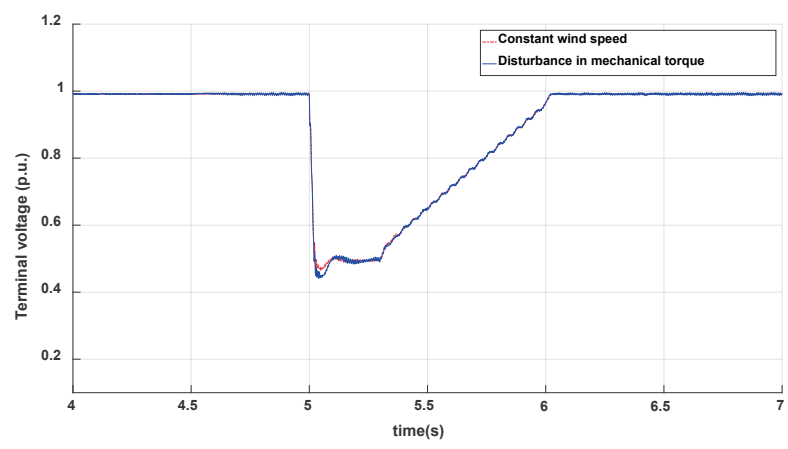

Figure 13 Terminal voltage under $40 \%$ voltage dip

It should be noted that initial generation for a population size considered 400 particles and fitness function was minimized after 120 iterations of PSO algorithm which in PI parameters have been tuned very well and given in Appendix. In this case, the convergence of fitness function is also presented in Fig 14.

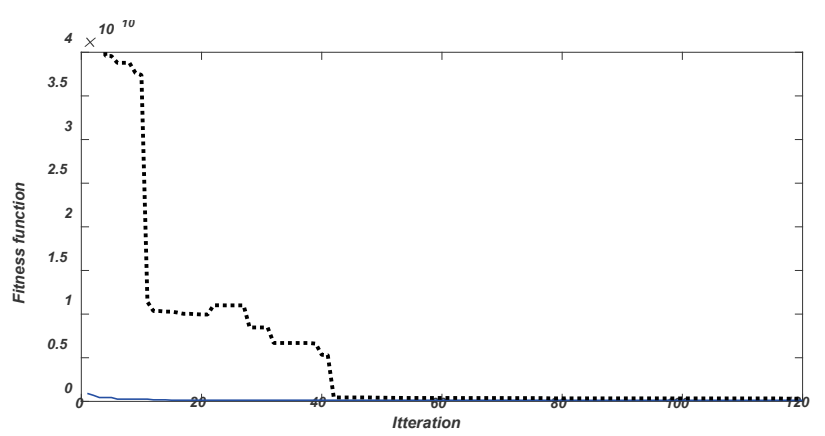

Figure 14 Convergence of fitness function
Fig. 15 to Fig. 20 show the DFIG-based wind turbine response to wind speed variation and uncertainty under $40 \%$ symmetric three-phase voltage dip in the network. Fig. 15 and 16 show the active and reactive power of the DFIG stator respectively, in both cases; (1) constant wind speed, (2) disturbance in mechanical torque (wind speed uncertainty and the step increase of wind speed). As can be seen in Fig. 15 and 16, the variations of the active and reactive power are in accordance with the variations of mechanical torque. In addition, in presence of wind speed uncertainty, the oscillation of the active and reactive power is more under voltage dip condition. As it can be seen, PI controllers work acceptably and track reactive and active power references well in normal conditions

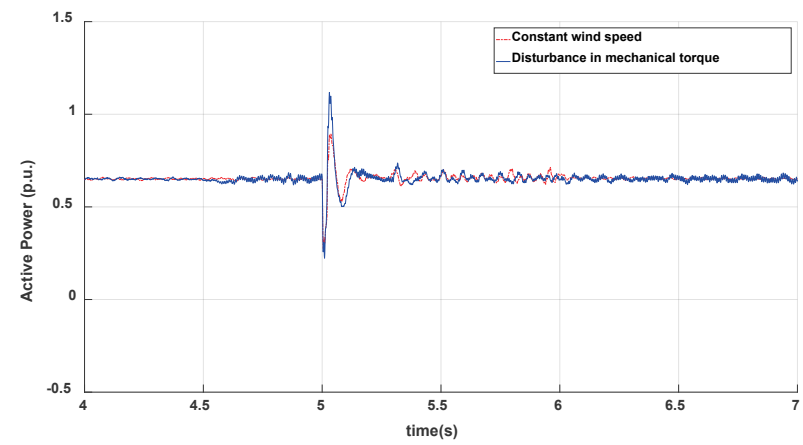

Figure 15 Active power under $40 \%$ voltage dip

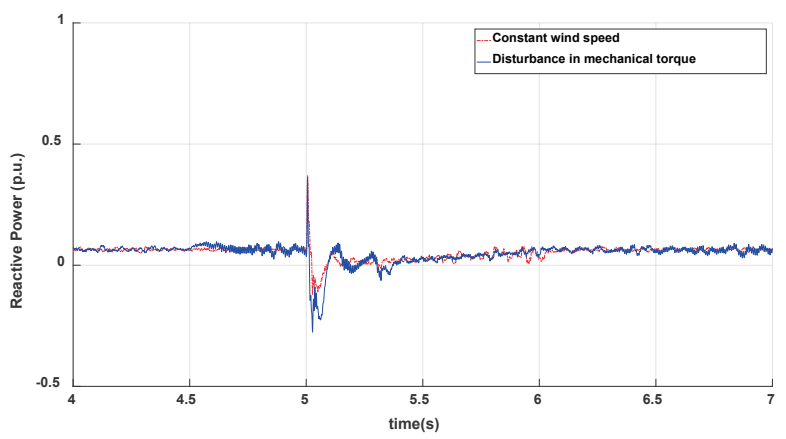

Figure 16 Terminal voltage under $40 \%$ voltage dip

In addition, the variations of the average value generator speed have been shown in Fig. 17 due to the increase of the average value of mechanical torque. From Fig. 18, in spite of increasing mechanical torque, the DClink voltage is controlled in normal condition, but during voltage dip conditions, when mechanical torque increases, the DC-link voltage increases more than when wind speed is constant. In the following, in Fig. 19 and Fig. 20, the dynamic responses of the rotor and stator current of the DFIG have been given, respectively. Similarity to Fig. 18, under voltage dip condition, wind speed uncertainty causes that the rotor current increases to 2 p.u.

With regard to the results, a voltage dip event causes fluctuation in active and reactive power similar to the other variables. However, the PI controllers could control the DFIG variable even in a faulted grid but for enhancing LVRT capability, DFIG needs the new control strategy to increase the PCC voltage in a faulted grid to cope with the rotor over-current and the DC-link over-voltage. The proposed method shows well that uncertainty should be considered in order to investigate the behaviour of the generator. The generator variables including active and reactive power suffer from severe transients under voltage 
dip condition. Depending on the results, the rotor current increases to 2 p.u. in which it can damage electronic devices because of the rating of their structure.

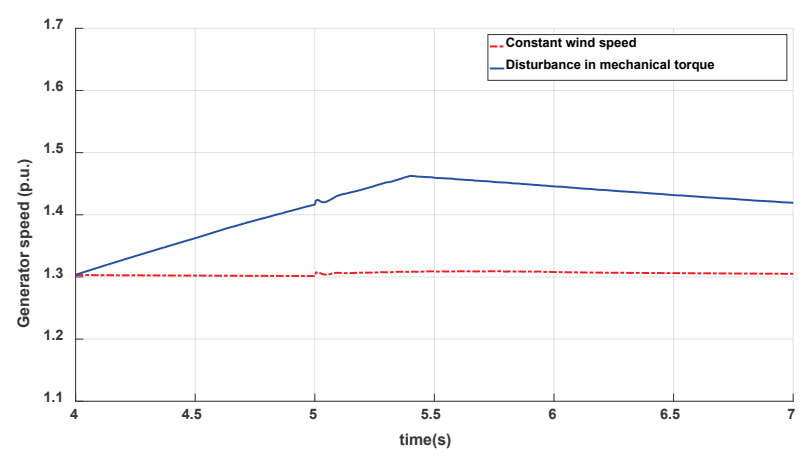

Figure 17 Generator speed under 40\% voltage dip

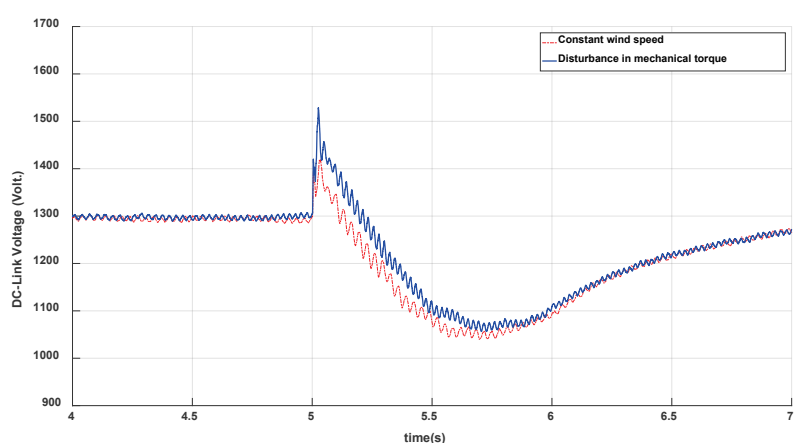

Figure 18 DC-link voltage under $40 \%$ voltage dip

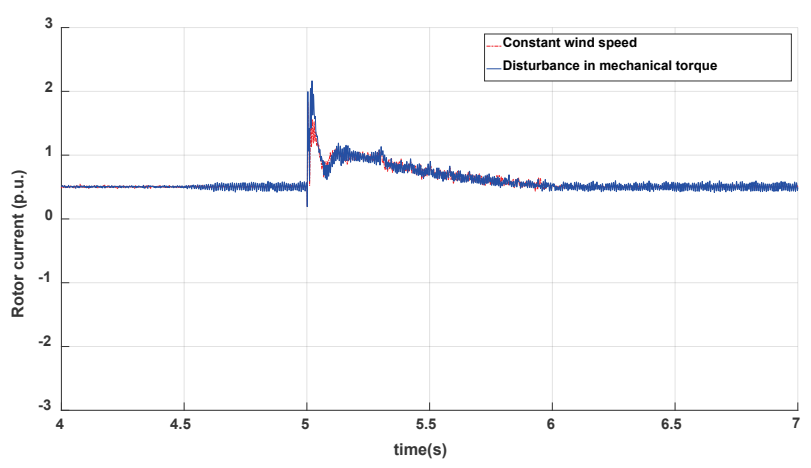

Figure 19 Rotor current under 40\% voltage dip

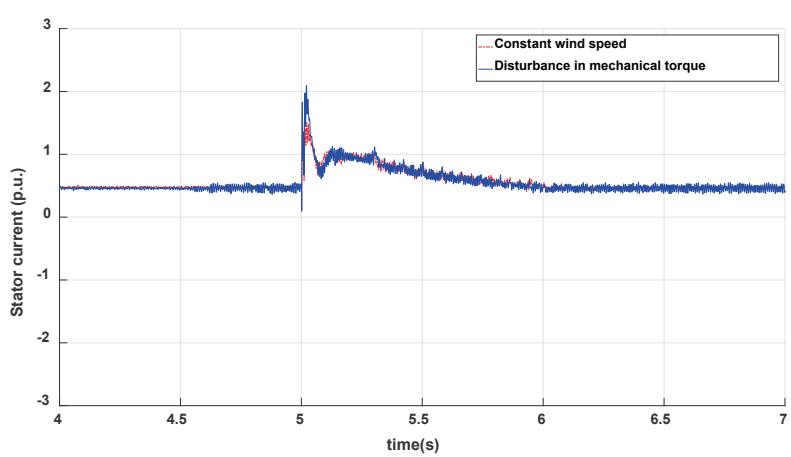

Figure 20 Stator current under $40 \%$ voltage dip

\section{CONCLUSIONS}

In this research, a discrete model of DFIG is used. PI controllers were frequently omitted in the DFIG. As it could be seen, without PI controllers, all of the variables of the DFIG are varied but GSC voltage regulator can help to control the DFIG without any tuned parameters of RSC voltage regulator. However, the PI controllers cannot control the DFIG-based wind farm during a voltage dip condition in the network. Although the results of the simulation show that the PI controllers drive RSC and GSC during normal condition and track the active and reactive power references as well, this method contributes to increase the rotor and stator current and DC-link voltage during a fault condition and is irregular under voltage dip condition. In addition, in this paper and many other papers, the consideration of the effect of saturation and uncertainty in the DFIG is not done. Therefore, the effect of saturation and a nonlinear model of DFIG-based wind farm must be considered, then controllers for DFIG are designed and tuned.

\section{Appendix}

DFIG-based wind farm parameters: Rated power DFIG $=1.5 \mathrm{MW}$, stator voltage $=575 \mathrm{~V}$, magnetization inductance generator $=2.9$ p.u., stator leakage inductance $=0.18$ p.u., rotor leakage inductance $=0.16$ p.u., rotor resistance $=0.016$ p.u., stator resistance $=0.023$ p.u., number of pair of poles $=3$, conversion ratio from stator to rotor: $575 / 1975$, frequency $=60 \mathrm{~Hz} ; H=0.658$.

PI parameters: $K_{p 1}=0.1, K_{i 1}=10, K_{p 2}=0.1, K_{i 2}=10$, $K_{p 3}=0.01, K_{i 3}=0.01, K_{p 4}=100, K_{i 4}=0.01, K_{p 5}=9.1551$, $K_{i 5}=77.7758$.

\section{REFERENCES}

[1] Doumi, M., Aissaoui, A. G., Abid, M., et al. (2016). Robust Fuzzy Gains Scheduling of RST Controller for a WECS Based on a Doubly-Fed Induction Generator. Automatika, 57, 617-626. https://doi.org/10.7305/automatika.2017.02.1241

[2] Shahzad Nazir, M., Wu, Q., \& Li, M. (2017). Symmetrical Short-Circuit Parameters Comparison of DFIG-WT. Int $J$ Electr Comput Eng Syst, 8, 77-83. https://doi.org/10.32985/ijeces.8.2.5

[3] Hosseini, E. \& Shahgholian, G. (2017. Output power levelling for DFIG wind turbine system using intelligent pitch angle control. Automatika, 58, 363-374. https://doi.org/10.1080/00051144.2018.1455017

[4] Tohidi, S. \& Behnam, M. (2016). A comprehensive review of low voltage ride through of doubly fed induction wind generators. Renew Sustain Energy Rev, 57, 412-419. https://doi.org/10.1016/J.RSER.2015.12.155

[5] Xiao, S., Yang, G., \& Zhou, H. (2011). A LVRT control strategy based on flux tracking for DFIG-based wind power systems. In: $8^{\text {th }}$ International Conference on Power Electronics - ECCE Asia, IEEE, 76-82.

[6] Yang, L., Xu, Z., Ostergaard, J., et al. (2012). Advanced Control Strategy of DFIG Wind Turbines for Power System Fault Ride Through. IEEE Trans Power Syst, 27, 713-722. https://doi.org/10.1109/TPWRS.2011.2174387

[7] Zhou, X., Tang, Y., \& Shi, J. (2017). Enhancing LVRT Capability of DFIG-Based Wind Turbine Systems with SMES Series in the Rotor Side. Int J Rotating Mach, 1-8. https://doi.org/10.1155/2017/4635452

[8] Döşoğlu, M. K. (2016). Hybrid low voltage ride through enhancement for transient stability capability in wind farms. Int J Electr Power Energy Syst, 78, 655-662. https://doi.org/10.1016/J.IJEPES.2015.12.018

[9] Döşoğlu, M. K. (2016). A new approach for low voltage ride through capability in DFIG based wind farm. Int $J$ Electr Power Energy Syst, 83, 251-258. https://doi.org/10.1016/J.IJEPES.2016.04.027 
[10] Sørensen, P. E., Hansen, A. D., Christensen, P., Mieritz, M., Bech, J., Bak-Jensen, B., \& Nielsen, H. (2003). Simulation and verification of transient events in large wind power installations. Denmark. Forskningscenter Risoe. Risoe-R, No. 1331(EN)

[11] Ozsoy, E. E., Golubovic, E., Sabanovic, A., et al. (2015). A Novel Current Controller Scheme for Doubly Fed Induction Generators. Automatika, 56, 186-195. https://doi.org/10.7305/automatika.2015.07.766

[12] Yang, J., Fletcher, J. E., \& O'Reilly, J. (2010). A SeriesDynamic-Resistor-Based Converter Protection Scheme for Doubly-Fed Induction Generator During Various Fault Conditions. IEEE Trans Energy Convers, 25, 422-432. https://doi.org/10.1109/TEC.2009.2037970

[13] Pannell, G., Zahawi, B., Atkinson, D. J., \& Missailidis, P. (2013). Evaluation of the Performance of a DC-Link Brake Chopper as a DFIG Low-Voltage Fault-Ride-Through Device. IEEE Trans Energy Convers, 28, 535-542. https://doi.org/10.1109/TEC.2013.2261301

[14] Abed, N. Y., Kabsha, M. M., \& Abdlsalam, G. M. (2013). Low Voltage Ride-Through protection techniques for DFIG wind generator. In: 2013 IEEE Power \& Energy Society General Meeting. IEEE, 1-6.

[15] Ghosh, S. \& Kamalasadan, S. (2017). An Energy FunctionBased Optimal Control Strategy for Output Stabilization of Integrated DFIG-Flywheel Energy Storage System. IEEE Trans Smart Grid, 8, 1922-1931. https://doi.org/10.1109/TSG.2015.2510866

[16] Wei, L., Joos, G., \& Belanger, J. (2010) Real-Time Simulation of a Wind Turbine Generator Coupled With a Battery Supercapacitor Energy Storage System. IEEE Trans Ind Electron, 57, 1137-1145. https://doi.org/10.1109/TIE.2009.2037103

[17] Döşoğlu, M. K. (2017). Nonlinear dynamic modeling for fault ride-through capability of DFIG-based wind farm. Nonlinear Dyn, 89, 2683-2694 https://doi.org/10.1007/s11071-017-3617-8

[18] Khamaira, M. Y., Shiddiq Yunus, A. M., Abu-Siada, A. (2013). Improvement of DFIG-based WECS performance using SMES unit. In: 2013 Australasian Universities Power Engineering Conference (AUPEC). IEEE, pp 1-5

[19] Wang, B., Qian, Y., \& Zhang, Y. (2013). Robust nonlinear controller design of wind turbine with doubly fed induction generator by using Hamiltonian energy approach. J Control Theory Appl, 11, 282-287. https://doi.org/10.1007/s11768-013-1116-0

[20] Iyasere, E., Salah, M. H., Dawson, D. M., et al. (2012). Robust nonlinear control strategy to maximize energy capture in a variable speed wind turbine with an internal induction generator. J Control Theory Appl, 10, 184-194. https://doi.org/10.1007/s11768-012-0315-4

[21] Song, H. \& Qu, Y. (2012). Energy-based modeling and control for grid-side converter of doubly fed wind generator. $J$ Control Theory Appl, 10, 435-440. https://doi.org/10.1007/s11768-012-1052-4

[22] Gayen, P. K., Chatterjee, D., \& Goswami, S. K. (2016). An improved low-voltage ride-through performance of DFIG based wind plant using stator dynamic composite fault current limiter. ISA Trans, 62, 333-348. https://doi.org/10.1016/J.ISATRA.2016.01.023

[23] Rahim, A. H. M. A. \& Nowicki, E. P. (2012). Supercapacitor energy storage system for fault ride-through of a DFIG wind generation system. Energy Convers Manag, 59, 96-102. https://doi.org/10.1016/J.ENCONMAN.2012.03.003

[24] Zhang, X., Cao, X., Wang, W., \& Yun, C. (2013). Fault Ride-Through Study of Wind Turbines. J Power Energy Eng, 01, 25-29. https://doi.org/10.4236/jpee.2013.15004

[25] Guo, W., Xiao, L., Dai, S., et al. (2015). Evaluation of the Performance of BTFCLs for Enhancing LVRT Capability of DFIG. IEEE Trans Power Electron, 30, 3623-3637.
https://doi.org/10.1109/TPEL.2014.2340852

[26] Ibrahim, A. O., Nguyen, T. H., Lee, D-C., \& Kim, S-C. (2011). A Fault Ride-Through Technique of DFIG Wind Turbine Systems Using Dynamic Voltage Restorers. IEEE Trans Energy Convers, 26, 871-882. https://doi.org/10.1109/TEC.2011.2158102

[27] Naderi, S. B., Negnevitsky, M., Jalilian, A., et al. (2017). Low voltage ride-through enhancement of DFIG-based wind turbine using DC link switchable resistive type fault current limiter. Int J Electr Power Energy Syst, 86, 104-119. https://doi.org/10.1016/J.IJEPES.2016.10.001

[28] Swain, S. \& Ray, P. K. (2017). Short circuit fault analysis in a grid connected DFIG based wind energy system with active crowbar protection circuit for ride through capability and power quality improvement. Int J Electr Power Energy Syst, 84, 64-75. https://doi.org/10.1016/J.IJEPES.2016.05.006

[29] Döşoğlu, M. K. (2017). Enhancement of SDRU and RCC for low voltage ride through capability in DFIG based wind farm. Electr Eng, 99, 673-683. https://doi.org/10.1007/s00202-016-0403-4

[30] Eddine, K. D., Mezouar, A., Boumediene, L., \& Van Den Bossche, A. P. M. (2016). A comprehensive review of LVRT capability and sliding mode control of grid-connected windturbine-driven doubly fed induction generator. Automatika, 57, 922-935. https://doi.org/10.7305/automatika.2017.05.1813

[31] Ozsoy, E. E., Golubovic, E., Sabanovic, A., et al. (2015). A Novel Current Controller Scheme for Doubly Fed Induction Generators. Automatika, 56, 186-195. https://doi.org/10.7305/automatika.2015.07.766

[32] Miller, N. W., Sanchez-Gasca, J. J., Price, W. W., \& Delmerico, R. W. (2003). Dynamic modeling of GE 1.5 and 3.6 MW wind turbine-generators for stability simulations. In: 2003 IEEE Power Engineering Society General Meeting (IEEE Cat. No. 03CH37491), IEEE, 1977-1983.

[33] Eberhart, R. \& Kennedy, J. (1995). A new optimizer using particle swarm theory. In: MHS'95, Proceedings of the $6^{\text {th }}$ International Symposium on Micro Machine and Human Science, IEEE, 39-43.

[34] Rafiee, Z. \& Meyabadi, A. F. (2012). Optimal design of power system stabiliser using a new cost function and PSO algorithm. Int J Power Energy Convers, 3, 253. https://doi.org/10.1504/IJPEC.2012.048042

[35] Rafiee, Z., Meyabadi, A. F., \& Heydari, H. (2015). PSS parameters values finding using SMVSDFT objective function and a new technique for multi-objective function in a multi-machine power system. Int J Power Energy Convers, 6, 252. https://doi.org/10.1504//JPEC.2015.070471

[36] Rezaei, M. M. (2018). A nonlinear maximum power point tracking technique for DFIG-based wind energy conversion systems. Eng Sci Technol an Int J, 21, 901-908. https://doi.org/10.1016/J.JESTCH.2018.07.005

\section{Contact information}

Zahra RAFIEE, MsS, in Electrical Engineering (Corresponding author)

Sahid Beheshti University, Faculty of Electrical Engineering,

Blv. Daneshjoo, Velenjak, Tehran, Iran, 1983969411

E-mail: z_rafiee@sbu.ac.ir

Mansour RAFIEE, PhD, in Electrical Engineering Sahid Beheshti University, Faculty of Electrical Engineering, Blv. Daneshjoo, Velenjak, Tehran,I ran, 1983969411 E-mail: m_rafiee@yahoo.com

Mohammadreza AGHAMOHAMMADI, PhD, in Electrical Engineering Sahid Beheshti University, Faculty of Electrical Engineering,

Blv. Daneshjoo, Velenjak, Tehran, Iran, 1983969411

E-mail: m.r.aghamohammad34@gmail.com 